\title{
Gênero e trabalho noturno: sono, cotidiano e vivências de quem troca a noite pelo dia
}

\author{
Gender and night work: sleep, daily life, \\ and the experience of night shift workers
}

\author{
Lúcia Rotenberg 1 \\ Luciana Fernandes Portela 1 \\ Willer Baumgartem Marcondes 1 \\ Cláudia Moreno 2,3 \\ Cristiano de Paula Nascimento 1
}

\footnotetext{
1 Laboratório de Educação em Ambiente e Saúde,

Departamento de Biologia, Instituto Oswaldo Cruz,

Fundação Oswaldo Cruz. Av. Brasil 4365,

Rio de Janeiro, $R J$

21045-900, Brasil.

2 Departamento de Saúde

Ambiental, Faculdade

de Saúde Pública,

Universidade de São Paulo.

Av. Dr. Arnaldo 715,

São Paulo, SP

02146-904, Brasil.

3 Grupo Multidisciplinar

de Desenvolvimento

e Ritmos Biológicos

Universidade de São Paulo.

Av. Lineu Prestes 1524,

São Paulo, $S P$

05508-900, Brasil.
}

\begin{abstract}
This paper deals with the impact of night work from a gender perspective, through a field study at a factory employing men and women on the night shift. It is based on data for hours of sleep over the course of several weeks, socio-demographic data,, and job information, using a semi-structured interview. The methodology includes chronobiological aspects of sleep (mainly quantitative data) and workers' discourse concerning gender-related experiences in the day-to-night switch. Despite gender issues and differences in daily life, the switch is perceived quite vividly by both men and women, permeating several aspects of life, like health, leisure, studies, and intimate personal relations. Quantitative sleep analysis showed more severe effects of night work on women, especially those with children. Such sleep patterns were associated with different expectations among men and women, revealing gender issues that are essential for understanding the reality of individuals who work odd hours.
\end{abstract}

Key words Night Work; Gender; Occupational Health; Chronobiology

Resumo O artigo trata do impacto do trabalho noturno sob o enfoque de gênero, através de trabalho de campo em uma indústria que emprega homens e mulheres no turno noturno. O estudo se baseia em informações sobre os horários de sono por várias semanas, dados sócio-demográficos e relativos ao trabalho profissional e em entrevistas semi-estruturadas. A metodologia considera aspectos cronobiológicos do sono - essencialmente quantitativos - e elementos discursivos dos/as trabalhadores/as sobre suas vivências - masculinas e femininas - da troca do dia pela noite. Em que pese as questões de gênero e diferenças quanto ao cotidiano, a inversão de horários é sentida de forma intensa por homens e mulheres, permeando diversos aspectos da vida, como a saúde, o lazer, os estudos e as relações amorosas. A análise quantitativa do sono revelou efeitos mais prejudiciais do trabalho noturno sobre as mulheres, particularmente as que têm filhos. Tais padrões do sono se articularam com as expectativas que recaem sobre os gêneros, revelando a profunda interrelação entre o trabalho profissional e a vida doméstica como geradoras de impactos à saúde, o que ressalta o caráter essencial das relações de gênero na compreensão da realidade vivida pelos que trabalham em horários não usuais.

Palavras-chave Trabalho Noturno; Gênero; Saúde Ocupacional; Cronobiologia 


\section{Introdução}

A análise das relações de gênero associadas ao trabalho noturno é uma demanda atual, já que o aumento da força de trabalho feminina inclui um contingente que trabalha à noite em indústrias, onde o turno noturno era restrito aos homens até recentemente (1988, no Brasil). Assim, pouco se conhece das especificidades da população feminina que trabalha à noite em espaços industriais.

O presente estudo parte do conceito de tempo biológico, segundo o qual as funções orgânicas diferem entre o dia e a noite, de forma que o trabalho noturno implica alterações não só na vida social, mas também no organismo. Os problemas decorrentes desta inversão são estudados pela Cronobiologia, área do saber que trata da organização temporal biológica, esclarecendo os mecanismos subjacentes a algumas dificuldades por que passam os trabalhadores e acrescentando, com isso, mais uma faceta às complexas relações entre trabalho e qualidade de vida.

A Cronobiologia estuda os ritmos biológicos - mudanças em variáveis fisiológicas ou comportamentais que se repetem regularmente, como a alternância entre a vigília e o sono ou o ciclo menstrual. Pesquisas na área revelam um encadeamento interno entre os ritmos, essencial à condição de saúde (Marques \& Menna-Barreto, 1997). Esta organização temporal compõe-se de ritmos de diversas freqüências, dos quais os de 24 horas (denominados circadianos) são os mais estudados. Quando uma pessoa trabalha à noite, ela passa a dormir de dia, mas outros ritmos biológicos (o de temperatura, por exemplo) não se modificam instantaneamente, o que leva à chamada dessincronização interna. Isso se manifesta quando a pessoa tenta dormir de dia, mas se sente alerta: na realidade, ela precisa repousar no momento em que seu corpo se prepara para a vigília (Minors \& Waterhouse, 1981). As refeições com a família, os estabelecimentos comerciais e o nível de ruídos seguem os horários "normais" da sociedade, contribuindo para prejudicar o sono diurno. Nesse sentido, o trabalho à noite está associado a um cotidiano essencialmente diferente do adotado pela comunidade em geral, no que concerne aos ritmos sociais e biológicos. Suas conseqüências incluem a insônia, irritabilidade, sonolência de dia, sensação de "ressaca" e mau funcionamento do aparelho digestivo, que levam a longo prazo à doenças relacionadas ao sistema gastro-intestinal e nervoso. São ainda observados efeitos à segurança do trabalho e à qualidade de vida dos(as) trabalhadores(as) e suas famílias (Fischer, 1996).

Ao analisar as condições de trabalho como fonte de impacto à saúde, deve-se reconhecer o papel das mulheres como responsáveis pelas atribuições domésticas - papel que tem se alterado pouco apesar da crescente participação feminina na força de trabalho (Bruschini, 1990; Sorensen \& Verbrugge, 1987). Quando realizados sob condições adversas, ambos os trabalhos (doméstico e profissional) afetam a saúde física e mental das mulheres, enquanto apenas o trabalho profissional tende a afetar a saúde nos trabalhadores do sexo masculino (Hall et al., 1990). O reconhecimento das diferenças (e desigualdades) entre homens e mulheres quanto ao dia-a-dia demanda abordagens que dêem conta da especificidade da situação feminina quanto à saúde (Garduño, 1997). Neste sentido, há que se usar novo instrumental de análise que leve em conta os papéis socialmente atribuídos a homens e mulheres, na medida em que eles envolvem diferentes fatores de risco à saúde (Aquino, 1996). O questionamento sobre o próprio conceito de "trabalho" pela sociologia de cunho feminista contribui para esta discussão quando se recusa a limitá-lo ao trabalho remunerado, propondo uma definição ampla que inclua o trabalho doméstico (Kergoat, 1989).

A relação saúde-trabalho, cujos efeitos de gênero têm sido pouco explorados (Brito, 1997; Messing, 1999), ganha novos contornos quando se trata do trabalho noturno, já que ele permite às mulheres lidar com as demandas duais dos trabalhos profissional e doméstico (Brown, 1982). Para elas, a escolha do turno está associada à conciliação do trabalho à noite com o cuidado dos filhos de dia, como mostram dados populacionais e estudos de caso (Lee, 1992; Walker, 1985).

A reorganização da vida cotidiana - de forma a acomodar o sono e as demais atividades do dia - pode ser difícil para as mulheres em função da dupla jornada. Assim, as diferenças entre homens e mulheres quanto ao lidar (do inglês coping) com o trabalho noturno têm sido atribuídas a fatores culturais, e não a características biológicas (Härma, 1995; Nachreiner, 1998). Neste contexto, o impacto do trabalho noturno sob a ótica de gênero envolve a realidade de homens e mulheres fora do trabalho, além de considerar sua relação com o processo de trabalho, particularmente os aspectos relacionados à divisão sexual do trabalho (Garduño, 1997; Kergoat, 1989).

Este estudo baseia-se em dois eixos identificados na literatura sobre o impacto do trabalho noturno à saúde: a privação do sono como 
questão central entre os que trabalham à noite, afetando de forma significativa o bem-estar físico e mental (Akerstedt, 1996) e a escassez de estudos que abordem a fala de trabalhadores(as) e suas vivências em relação ao "desafio temporal" decorrente de um ritmo de vida que contraria princípios biológicos e de convivência social. A idéia que norteia a pesquisa é a de que, se a abordagem cronobiológica do sono eminentemente quantitativa - é essencial na análise da privação de sono, por outro lado ela não dá conta dos fatores subjacentes à maior ou menor possibilidade de dormir, que dependem do cotidiano de cada um, podendo, portanto, ser sujeitos à influência de gênero. Aliamos o estudo quantitativo dos horários de sono às informações provenientes de uma metodologia qualitativa que buscasse apreender o significado que os(as) trabalhadores(as) atribuem ao sono e aos trabalhos profissional e doméstico, trazendo à tona suas vivências e práticas em relação à inversão de horários.

A pesquisa aqui descrita é parte de uma investigação maior realizada em etapas, quais sejam: (1) a caracterização do grupo quanto às variáveis sócio-demográficas e relativas ao trabalho profissional, (2) o estudo cronobiológico do sono, (3) a análise qualitativa das falas relativas à inversão de horários, (4) a complementação do estudo quantitativo do sono, com base no uso de equipamento portátil e (5) a análise dos trabalhos profissional e doméstico, incluindo a descrição dos ambientes físico e organizacional da fábrica, dos postos de trabalho e das tarefas domésticas realizadas por homens e mulheres. Os resultados gerais dessas etapas foram apresentados na forma de relatório (Rotenberg et al., 1999). Este artigo refere-se às etapas 1 a 3, tendo por objetivos analisar quantitativamente o sono de trabalhadores e trabalhadoras e apreender suas percepções sobre o trabalho noturno, sob o enfoque das relações de gênero.

\section{Metodologia}

O trabalho de campo foi realizado em uma fábrica do setor de plásticos no Rio de Janeiro, que produz embalagens para colônias, xampus e similares. Nos setores da produção que têm atividade noturna, a jornada de trabalho é de 22 às $6 \mathrm{~h}$ de segunda à sexta-feira, com folgas nos fins de semana. $\mathrm{O}$ estudo incluiu todos os trabalhadores do turno da noite (60 pessoas), porém nem todas as pessoas participaram de toda a pesquisa, devido a demissões e ao remanejamento de pessoal. Os dados sócio-demográficos e o estudo quantitativo do sono (eta- pas 1 e 2) referem-se ao conjunto de 46 pessoas (30 mulheres e 16 homens) que participaram de ambas as etapas; a análise das entrevistas refere-se a dez pessoas (cinco homens e cinco mulheres) selecionadas segundo critérios descritos no respectivo item. Os procedimentos de coleta e tratamento dos dados são apresentados a seguir.

\section{Etapa 1: dados sócio-demográficos e relativos ao trabalho profissional}

Aplicamos um formulário que incluía dados relativos às variáveis sócio-demográficas e à atividade desenvolvida na fábrica, o tempo de trabalho noturno e a ocorrência de outra ocupação.

\section{Etapa 2: a cronobiologia do ciclo vigília-sono}

Utilizamos folhas de registro nas quais os(as) trabalhadores(as) assinalavam os horários de sono, trabalho e tempo livre (F. M. Fischer, comunicação pessoal; Knauth et al., 1983) por sete semanas consecutivas. Neste período, mantivemos dois contatos semanais com os(as) trabalhadores(as), acompanhando os registros e esclarecendo as dúvidas.

O estudo cronobiológico do sono visou complementar dados preliminares (Rotenberg et al., 2000a). Analisamos o sono diurno ocorrido entre noites consecutivas de trabalho com base no número de episódios de sono por dia, na duração do primeiro sono do dia e na duração total do sono por dia. Comparamos estes parâmetros (a) entre as amostras masculina e feminina, (b) entre as mulheres que têm e que não têm filhos de até dez anos e (c) entre os homens que têm e que não têm filhos nesta faixa etária, que se baseia em estudo anterior (Rotenberg et al., 2000b). Utilizamos o teste U de Mann-Whitney, adotando o nível de significância de 5\% (Zar, 1996).

\section{Etapa 3: a análise das entrevistas}

Adotamos uma metodologia qualitativa baseada em entrevistas semi-estruturadas, abordando aspectos gerais do trabalho noturno, vantagens, desvantagens e seus efeitos no cotidiano, principalmente na organização das atividades. $O$ roteiro abordava ainda as percepções sobre o sono, a fadiga e a saúde, assim como suas mudanças a partir do trabalho noturno. Também inquirimos sobre as atribuições e relações de gênero dentro e fora da fábrica, no dia-a-dia dos entrevistados.

Para selecionar o grupo de dez pessoas (cinco homens e cinco mulheres) cujas entrevistas 
foram analisadas, contemplamos a diversidade observada quanto a situação conjugal e a presença de crianças em casa, que elegemos como fatores relevantes na compreensão do cotidiano, incluindo os horários de sono. O grupo era composto de dois homens solteiros e três casados (incluindo união livre), dentre os quais dois tinham filhos de até dez anos. Quanto às mulheres, duas eram solteiras, duas casadas e uma separada; com exceção das solteiras, todas tinham filhos naquela faixa etária.

As falas foram analisadas a partir da transcrição integral e literal das fitas gravadas nas entrevistas. A partir da construção de familiaridade com os textos, elaboramos dois recortes gerais que agruparam os trechos que abordavam (1) o sono, com ênfase nas experiências de dormir de dia, hábitos, queixas e alternativas adotadas e (2) as Relações de Gênero, reunindo relatos sobre as diferenças entre homens e mulheres no trabalho doméstico, seus impactos na vida afetiva, sexual, social e familiar. Com estes recortes, trabalhamos com as entrevistas como um conjunto, selecionando as falas mais ilustrativas para compor um "mosaico" de significados, encadeados na forma de um texto que procurou seguir as argumentações em suas próprias lógicas e ambivalências.

\section{Aspectos éticos}

No primeiro encontro com os(as) trabalhadores (as), apresentamos a equipe mencionando o vínculo com a Fundação Oswaldo Cruz (FIOCRUZ) - instituição de pesquisa voltada para a saúde pública - em oposição ao vínculo com o gerente da empresa, que teria apenas nos autorizado a freqüentar a fábrica. Explicamos em linhas gerais o projeto e, ao convidá-los a participar, deixamos claro o caráter voluntário da participação, com liberdade de desistência a qualquer momento. Lemos em voz alta o Termo de Consentimento Livre e Esclarecido, nos moldes recomendados pela Resolução 196/96, referente aos aspectos éticos de pesquisas com seres humanos.

\section{Resultados}

Etapa 1: perfil sócio-demográfico e relativo à atividade profissional

A amostra feminina incluiu trabalhadoras com idade entre 20 e 47 anos, com valor médio de 33 anos. Entre os trabalhadores, a idade variou entre 24 e 47 anos, com valor médio de 36 anos.
A situação conjugal diferiu bastante entre homens e mulheres: a amostra masculina era composta prioritariamente de homens casados, incluindo união livre (75\%), seguida dos solteiros (19\%), sendo um trabalhador separado (6\%). A distribuição foi mais homogênea entre as mulheres, com valores percentuais de $40 \%$, $33 \%$ e $27 \%$, respectivamente. A maioria das pessoas tinha filhos; $60 \%$ das mulheres tinha filhos de até dez anos, ao passo que 50\% dos homens tinha filhos nesta faixa etária.

A amostra masculina incluía supervisores, mecânicos, controladores de qualidade e profissionais que fazem o transporte da matériaprima. As mulheres trabalhavam na linha de produção como embaladeiras ou operadoras de máquina, sendo a única exceção referente a uma delas, que atuava no controle de qualidade. O tempo de trabalho noturno diferiu bastante entre os dois grupos. A maioria dos homens (69\%) trabalhava à noite há mais de um ano, ao passo que um percentual semelhante de mulheres $(70 \%)$ trabalhava à noite há menos de um ano, ressaltando-se que $50 \%$ delas atuavam neste turno há menos de seis meses. Apenas dois trabalhadores tinham outra ocupação regular, ambos atuando como zeladores de prédio três dias por semana, de manhã.

\section{Etapa 2: análise cronobiológica do sono diurno}

O grupo estudado apresentou diferentes padrões quanto ao número de episódios e à duração do sono. Algumas pessoas dormiam regularmente uma vez por dia, outras, duas vezes, enquanto um terceiro grupo dormia ora uma vez, ora duas vezes por dia. A maioria das pessoas costumava dormir de manhã, ao voltar da fábrica, sendo o horário de início do sono anterior às 10 horas em $90 \%$ das mulheres e em $81 \%$ dos homens.

As amostras masculina e feminina diferiram apenas em relação à duração do primeiro sono ( $U=154,5 ; p=0,049)$; as medianas de 5,5 e de 4,6 horas, respectivamente, indicam que as mulheres tendem a dormir menos de manhã, quando comparadas aos homens. Considerando as diferenças entre as duas amostras quanto ao tempo de trabalho noturno, fizemos comparações adicionais relativas exclusivamente às pessoas que trabalhavam à noite há pelo menos um ano, que constituem um grupo de 11 homens e nove mulheres. Tais comparações confirmam a menor duração do sono matutino entre as mulheres $(U=24 ; p=0,053)$, com medianas de 5,4 e de 4,2 horas, nos homens e mulheres, respectivamente; os resulta- 
dos apontam, ainda, para uma redução da duração total do sono por dia entre as trabalhadoras, quando comparadas aos colegas do sexo masculino ( $U=20,0 ; p=0,025)$; com medianas de 7,8 e 7,0 horas, respectivamente.

Nenhum efeito significativo da presença de crianças sobre o sono foi observado na amostra masculina. Quanto às trabalhadoras, as que têm filhos dormem mais vezes por dia $(U=50,5$; $\mathrm{p}=0,015$ ), quando comparadas às que não os têm, havendo uma tendência entre elas à redução do sono matutino $(U=66,0 ; p=0,075)$, neste caso um resultado próximo ao limite da significância.

\section{A fala dos trabalhadores e trabalhadoras}

Homens e mulheres compartilham a percepção de que o trabalho noturno implica grandes mudanças em suas vidas. A necessidade de se manter em vigília à noite e de repousar de dia permeia vários aspectos da vida, como a saúde, o cotidiano, o lazer, os estudos, assim como as relações amorosas (os nomes abaixo são fictícios).

\section{- Como ficam o sono e a vigília}

Ao longo dos relatos, a menção ao sono e à vigília permite depreender uma seqüência de temas que vão desde a descrição desses estados e da interferência de fatores sociais e ambientais sobre eles, até as análises explicativas sobre as conseqüências de se experimentar repetidamente a inversão de horários, que envolve não só a vigília noturna e o sono diurno, mas também o "desencontro" em relação aos horários da família e da comunidade em geral. A expressão "a noite foi feita para dormir" está presente explicita ou implicitamente em diversas falas, como neste caso: "Porque o ser humano cansa né, tem sono... ainda mais no período da noite, eu acho que a noite não foi feita para você trabalhar, você tem que dormir..." (Sabrina).

Dormir à noite parece fazer parte da ordem natural das coisas. A alteração desta ordem é percebida pelo corpo ou pela mente, que se comunicam com a pessoa, seja pedindo para dormir, seja, mais enfaticamente, cobrando o sono: "Quer dizer, você está cansada... o seu organismo está pedindo sono e você está fazendo ao contrário do que ele está pedindo" (Elvira).

A percepção de que o corpo sabe que horas são e que a troca do dia pela noite não é inócua, aparece através da constatação recorrente de que o sono diurno é qualitativamente inferior ao noturno: "Você dorme porque tem que dormir, mas descansar o corpo, não descansa não" (Américo).
Diversos fatores contribuem para o dormir mal de dia, abrangendo desde o ambiente físico onde o sono se realiza, até os compromissos socialmente definidos que condicionam o diaa-dia. Entre as condições ambientais que prejudicam o sono, o calor e o ruído são os mais freqüentemente referidos, aparecendo juntos, às vezes. Os ruídos geralmente envolvem a presença de crianças em casa ou na vizinhança. Independentemente da fonte de ruído, este é muitas vezes percebido como dotado da capacidade de penetrar a cabeça, perturbando sobremaneira o sono: "Se eu ouvir uma pessoa conversando assim, aí pronto, aquilo dali parece que fica dentro da minha cabeça... aí ai meu Deus do céu" (Laura).

Por sua vez, o espaço físico reduzido favorece ainda mais a concentração dos ruídos e até a propagação dos odores: "É apertado, né... é só um cômodo e dividido. (...) Então... minha esposa está fazendo uma fritura, o cheiro da gordura, do óleo quente vai lá no meu nariz e eu acordo. Às vezes eu acordo sufocado (...) o cheiro vai no nariz..." (Pedro).

Já a claridade parece afetar menos o sono, se comparada ao efeito do calor: "Tem só a claridade do dia... mas a minha esposa fecha a janela, aí (...) tem que estar um tempo fresquinho, se tiver calor... vai atrapalhar. (...) Que prejudica mesmo é calor" (Pedro).

A dificuldade em dormir de dia parece surpreender uma das trabalhadoras, ao perceber que não é o barulho das crianças, nem a claridade que prejudicam o seu sono: "Não é nem o barulho, nem a claridade, é que eu não consigo dormir, mesmo" (Elvira).

\section{- O dia-a-dia fora da fábrica}

Diversos aspectos interferem na qualidade e na quantidade do sono de um trabalhador do turno noturno. Tais aspectos se articulam, dentro e fora do trabalho, no cotidiano de cada um, principalmente no que diz respeito à divisão de trabalhos domésticos e responsabilidades familiares. Assim, as demandas do dia-a-dia são de suma importância no que concerne à possibilidade de dormir e aparecem como o maior divisor de águas entre homens e mulheres. Os cuidados com a limpeza e a arrumação da casa, o preparo das refeições, a atenção às crianças freqüentemente foram mencionados por homens e mulheres como atribuições que sobrecarregam especialmente a trabalhadora, comprometendo gravemente seu tempo para dormir: "A gente chega em casa (...) tem que dividir o descanso com as tarefas domésticas entendeu, e fica meio complicado, porque você fi- 
ca assim meio desequilibrada: ou você descansa ou você cuida das tarefas, ou você cuida dos filhos entendeu?" (Elvira).

Tal sobrecarga para as mulheres ocorreria em função da atribuição dos trabalhos domésticos como uma característica essencialmente feminina que, por sua vez, nas relações de gênero, se articula com uma prerrogativa masculina que facilitaria a ausência dos homens nestas mesmas atividades. Desta forma, pudemos ouvir das mulheres falas muito claras sobre este caráter de "obrigatoriedade" dos cuidados domésticos: "Você tem que chegar em casa, fazer sua obrigação" (Marina).

Mas também ouvimos falas que, em tom de reclamação, apontam a prerrogativa dos homens de não adesão aos trabalhos da casa, tanto como um agravante da sobrecarga feminina, quanto como uma vantagem que permite a eles dormir mais e, portanto, se adaptar mais facilmente ao trabalho: "Porque o homem já tem uma vantagem, ele já tem comida pronta, roupa lavada, tudo certinho, ali. A gente tem que fazer, se a gente não fazer quem vai fazer?" (Marina).

Por sua vez, os homens confirmam que em sua rotina diária a prioridade é dormir. Dormem porque precisam se preparar para o turno noturno mas, também, porque podem se entregar mais livremente à satisfação desta necessidade: "Em casa eu não faço quase nada, não, entendeu? Trabalho só mais é aqui mesmo. (...) Chego em casa, tomo café, deitei... tô dormindo" (João).

Entre as donas-de-casa, os horários de sono são claramente determinados pelas "brechas” entre uma atribuição doméstica e outra. Também entre os homens, a disponibilidade de tempo para dormir varia em função do maior ou menor comprometimento com outras atividades, mas para eles as tarefas domésticas parecem não afetar o sono, a ser de forma eventual: "Fazer as coisas em casa e depois ir dormir... e o tempo que sobra pra gente dormir é pouco, né?" (Marina). "Não levanto para nada (...) só se acabar um gás, aí eu levanto para trocar o botijão" (Américo).

A menção à necessidade de resolver assuntos de dia, que também reduz o tempo para dormir, ressalta o "desencontro" em relação aos horários de funcionamento dos estabelecimentos: "Você fica na rua... você sai daqui 6 horas... aí, pô, eu tenho que ir no banco, o banco abre 10 horas. Já perde tempo de você tá dormindo em casa..." (Marina).

\section{- A saúde física e mental}

Para os que trabalham à noite, dormir está intimamente relacionado às condições de saúde: "Quando vai chegando a tarde (...) eu vou vendo que está passando a hora e eu não consigo dormir, então eu já começo a me tremer, sinto aquele tremor assim... às vezes dá uma sensação de taquicardia, que o meu coração vai sair pela boca (...) eu me sinto nervosa" (Elvira). "A saúde tô é normal, só que a gente tem que dormir um pouco. Ao menos quatro horas, cinco horas, no mínimo, porque, se não dormir, não trabalha..." (João).

A necessidade imperiosa de dormir por vezes se mescla com a necessidade também imperiosa de realizar as tarefas domésticas, gerando grande tensão: "Engordei mais, estou mais estressada,... fico nervosa. Vou até no médico pra ver se o médico passa um remédio pra mim. (...) Você trabalhando de dia você não sente a hora, mas quando você esta em casa de dia você sente que a hora tá passando e você não tem nada. (...) Você tá ali deitado, ah, quero levantar e o caso é que você não pode levantar, você tem que dormir. A obrigação é dormir, entendeu? (...) Se eu não dormir, eu vou me ferrar depois" (Marina).

Esta tensão também se expressa na contundência de algumas falas que descrevem situações em que é preciso interromper o sono: " $E u$ deito um pouquinho e acordo lá pras 11 horas, mas é um sono terrivel, apavorante! (...) Porque você acorda assustada. (...) porque você cortou o sono e você fica meia aérea" (Marina). "Quando você começa a pegar no sono, vem alguém te acordar, (...) você trabalhou à noite, chegou de manhã, você vai deitar assim, você percebe o sono chegando, chega alguém para te chamar (...) o corpo reage de uma forma sabe, você sente uma fraqueza, tipo uma febre, é uma coisa muito forte (...) tipo a bateria está... descarregando (...) você tem que atender a pessoa e deitar urgente entendeu, é como se você tivesse a possibilidade de morrer ali (...) Às vezes chega a Light lá, vai mexer, aí eu tenho que abrir o portão" (Nelson).

As mudanças de hábitos associadas ao trabalho noturno envolvem também a alimentação: "Mudou porque... na maneira de comida mudou. Já quando acorda, é hora de almoço. Hora de almoço é tudo descontrolado. (...) Tenho mais controle mais não." (João).

Algumas falas enfatizam o impacto à saúde e ao bem-estar através de uma percepção quase visceral das relações entre o corpo e a mente. Neste relato, Pedro se refere a expressões como "nervos trabalhando" e "mundo de abalo", 
articulando sua agressividade com os problemas decorrentes do horário de trabalho, que seriam mediados através de maus hábitos adquiridos no trabalho noturno, como o excesso de café e cigarro: "Mudou. (...) Eu peguei envelhecimento precoce. Eu tenho 44, 45 anos... tem pessoas que aparentam que eu tenho 60 entendeu? (...) Porque você... eu estou acordado agora e vou estar dormindo mais tarde, lá pelo meio dia, mas a consciência da gente está trabalhando, os nervos estão trabalhando entendeu? Nós vivemos em mundo de abalo (...) Não dorme, não tem aquele descanso espiritual (...) aquela coisa gostosa, aquele silêncio... não tem, a trepidação de tudo durante o dia, qualquer movimento do dia está te abalando (...) Você estar com aparência de acabado, por quê? Sua carne, seu organismo está cansando entendeu? (...) aí o seu corpo vai começando a murchar entendeu? (...) Um pouco agressivo. (...) Eu não sei se é porque eu... trabalhar à noite e trabalhar de dia é... sei lá, dá muito nervoso, porque eu fumo, tomo café direto né? (...) ocê toma café à noite e toma café de dia, quem trabalha de dia só toma o café de dia, de noite está dormindo. E eu não, eu tomo café de dia, de noite, a noite toda e uma boa parte do dia. Aí aquilo também pode causar abalo de nervo né? E se eu fumo um maço de noite, de cigarro, eu já vou passar a fumar dois" (Pedro).

A menção ao "nervoso" associada ao desânimo também são atribuídos à mudança de rotina: "No começo, eu conseguia dormir bem sabe, mas à medida que foram passando os dias, aí não sei se é o nervoso também, porque esse serviço à noite descontrola um pouco a gente... sabe, na parte de sistema nervoso (...), então eu passo praticamente a minha vida toda dormindo tendo sono normal, (...) fora o serviço, nunca tive insônia, aí (...) de repente eu quebro essa rotina, mudo, fico a noite inteira acordada... quer dizer, o corpo sente né? (...) Aí, quer dizer, minha vida mudou completamente, eu não tenho ânimo mais para nada" (Elvira).

O desânimo e o cansaço também prejudicam os estudos: "Eu tenho que ver curso, porque minha mãe fala: 'você não pode viver o tempo todo enfiada o tempo todo dentro da fábrica, mal ou bem você tem estudo, você sabe ler e escrever... tem que acabar o estudo... porque você não faz curso disso, o curso daquilo...' eu falo: mãe, às vezes eu estou tão sem pique para nada, que dá vontade de chegar, deitar e dormir..." (Sabrina).

A necessidade de dormir também adentra o fim de semana, prejudicando o lazer: "Porque são muitos sonos atrasados, são o quê? São segunda, terça, quarta, quinta e sexta... aí só... aí larga no sábado (...) Ficam 5 dias atrasados... Ó, sábado, eu não agüentei ver a 'Praça é Nossa'... e domingo eu não vi o 'Topa Tudo Por Dinheiro'... Não adianta, (...) O sono bate, mesmo sem querer você dorme" (Clarice).

\section{- Encontros e desencontros} nos relacionamentos amorosos

No encontro e desencontro entre turnos de trabalho, a intimidade dos casais que convivem parece ser a mais comprometida, segundo as trabalhadoras: "Porque fica chato, a gente levanta para trabalhar e fica ele e ofilho lá sozinho... quer dizer, de noite é hora da pessoa deitar na cama, relaxar, conversar né? Aí não, a pessoa vai... a mulher levanta e vai" (Clarice).

Quando perguntada diretamente se as repercussões do trabalho noturno também se fazem sentir em sua vida sexual, esta entrevistada confirmou que: "De dia você está cansada, tem coisa para fazer, você nem está se ligando nessas coisas...(...) E de noite não está em casa" (Clarice).

Entretanto, a interferência do desencontro de horários na vida sexual foi mencionada de forma mais contundente pelos homens entrevistados, deixando entrever intensa preocupação com seu desempenho sexual e a impressão que suas parceiras terão deles: "Você sente que o organismo não está muito disposto a uma atividade sexual (...) Às vezes você pode até dormir com a pessoa ali (...) já aconteceu comigo sabe, eu achei que eu estava tão animado, chegou na hora eu dormi.(...) Dormi porque eu estava muito cansado" (Nelson). "O trabalho noturno afasta um pouco a gente do relacionamento sexual com a esposa... (...) Muito, muito né? Você está em casa de dia, todo mundo acordado... como é que você vai transar? Por exemplo, vai dar uma transada com a esposa de dia, você fica brocha bicho.. (...) Se você estiver preocupado que vai chegar alguém, você tem $40 \%$ de queda à 50 ... no teu pênis, pô, cai, cai, cai... ele não brocha de tudo, mas você perde... (...) e eu sei que a culpa não é minha, mas sim da minha preocupação. (...) Porra, para a minha mulher eu sou brocha." (Pedro).

O ritmo de trabalho e o cansaço no fim de semana também afetam a relação com o namorado ou, mesmo, a oportunidade de "arrumar alguém", nas palavras de Elvira: "A melhor coisa para você sair geralmente é à noite, e à noite é quando eu estou aqui. Às vezes calhou de eu perder assim... até uma pessoa, um companheiro porque às vezes... toda vez que me chamava para sair eu nunca podia (...) quer dizer, qual é o homem que vai querer ficar com uma mulher que não tem tempo para ele?" (Elvira). 
"Ele (o namorado) acha que atrapalha (...) às vezes quando ele está a fim de sair e que eu me jogo no sofá e falo: ah Marcelo, eu não vou, estou cansada" (Sabrina).

\section{Discussão}

Os resultados revelam uma dimensão do trabalho que aparentemente independe do processo de trabalho em si, mas sim do fato de este ser realizado à noite. "Lidar" com o trabalho noturno mobiliza os trabalhadores e trabalhadoras em várias esferas da vida, uma mobilização que se expressa na preocupação permanente em dormir e descansar tanto durante a semana quanto no domingo, como se a demanda do trabalho (no caso, o horário de trabalho) os acompanhasse de perto, mesmo fora da fábrica. A ligação diuturna com o trabalho é particularmente evidente na fala de Clarice, que se refere à desvantagem de voltar para o trabalho no mesmo dia em que sai do trabalho, o que é diferente das pessoas que trabalham de dia, que só voltam no dia seguinte: "No caso é o quê? É meia noite e 15... ontem foi quarta né? Eu vim para cá 10 horas da noite... hoje já é quinta, quem trabalhou de 6 às 2 (14h), de 2 às 10 (14 às 22h), trabalha na quinta, a gente não, a gente vem quarta 10 horas da noite... aí já pulou para quinta (...) quer dizer, vamos sair hoje 6 horas, $e$ voltar na mesma quinta 10 horas da noite." (Clarice).

Esta estrutura temporal do trabalho, que envolve um turno fixo (somente à noite) com folgas nos fins de semana, é relativamente comum em indústrias que não requerem sistemas contínuos de trabalho. Se este esquema é vantajoso, se comparado a turnos contínuos, por preservar o fim de semana livre, por outro lado, ele implica uma seqüência de noites de trabalho, de forma que o tempo de folga é muitas vezes dedicado a reparar o cansaço da semana. Como comenta Seligman-Silva (1994:222), o cansaço e a sonolência acumulados levam a pessoa a vivenciar o sono "como um entrave que limita o prazer e a liberdade nas horas do não trabalho".

Sob vários aspectos, o corpo mostra que ele sabe que horas são, seja cobrando o sono e o repouso de noite, seja pagando o preço de desrespeitar este saber, através de efeitos diretamente ligados à privação do sono - como o desânimo, a fraqueza e a insônia, eventos corporais físicos - como o tremor, a obesidade e o envelhecimento precoce - e aspectos essencialmente psíquicos - como o descontrole e a agressividade. São falas marcadas pela menção ao "nervoso" que atuaria, como propõe Duarte (1998), como um código cultural amplo, mediando ou traduzindo condições de vida que podem eventualmente levar ao desencadeamento de perturbações.

A inversão de horários é sentida de forma intensa por homens e mulheres. Ao descrever o cotidiano, o ruído (de crianças, vizinhos ou carros) aparece não só como o fator que mais prejudica o sono, mas também como parte inevitável de uma sociedade diurna. O desencontro de horários se destaca na fala de um trabalhador que se refere à necessidade de atender ao funcionário da Light (que trabalha de dia), associando a interrupção do sono à sensação de febre e à imagem de uma bateria descarregando. No âmbito familiar, esse desencontro afeta o relacionamento com o cônjuge, remetendonos a estudos sociológicos que revelam efeitos danosos do trabalho em turnos sobre o tempo e a qualidade da convivência com a família (Volger et al., 1988). De fato, o conjunto de relatos reflete uma profunda noção de que o organismo, a mente e a sociedade têm os seus horários de funcionamento e que estes não são compatíveis com os de quem trabalha à noite.

Em que pese as diferenças quanto ao cotidiano e ao meio familiar, o trabalho noturno demanda uma reformulação geral de hábitos. Se a angústia e tensão de "ver o tempo passar e não conseguir dormir" por vezes está associada à incapacidade de pegar no sono de dia, em outros casos, elas decorrem da necessidade de conciliar o tempo de sono com as tarefas em casa. É neste momento que a carga e a mobilização em relação ao trabalho - que envolvem um sofrimento comum a homens e mulheres dão lugar à experiência tão feminina de realizar o trabalho doméstico. E é a partir deste trabalho que as diferenças de gênero se manifestam de forma mais vívida, seja em relação ao que as pessoas sentem como dificuldade no trabalho noturno, ao que fazem para lidar com elas ou a como interpretam a maior ou menor capacidade de se adaptar ao trabalho. Em resumo, embora haja uma carga partilhada por homens e mulheres, o envolvimento delas com as atribuições domésticas dá uma qualidade diferente ao cotidiano fora da fábrica, já que implica menor disponibilidade de tempo para outras atividades, incluindo o dormir.

As diferentes expectativas que recaem sobre os gêneros se articularam com os padrões quantitativos do sono diurno, como se depreende das comparações estatísticas entre as amostras masculina e feminina. Ao tratar deste ponto, deve-se considerar que os homens, em sua maioria, estavam minimamente adaptados 
ao trabalho noturno, enquanto muitas operárias haviam recém-ingressado neste turno. Neste contexto, o estudo do sono em grupos mais homogêneos (com mais de um ano de trabalho noturno) se mostra adequado, particularmente quando se leva em conta o papel central do sono para as pessoas que trabalham à noite (Robson \& Wedderburn, 1990). Tais comparações revelaram menor duração total do sono por dia entre as mulheres, confirmando os dados de Dekker \& Tepas (1990) e Oginska et al. (1993). O cotidiano essencialmente voltado para a casa e os filhos se manifestou no ciclo vigília-sono, podendo ser entendido em seus significados mais subjetivos através das entrevistas. Assim, a análise das falas e o estudo cronobiológico do sono, que envolvem conteúdos tão diferenciados, puderam ser tratados em conjunto como forma de melhor interpretar a realidade, como previa o planejamento da pesquisa em etapas complementares.

Para além do uso combinado de métodos das Ciências Sociais e da Biologia, o estudo busca a integração (e não a comparação ou o confronto) entre disciplinas como forma de apreender as complexas vivências que homens e mulheres enfrentam nos seus cotidianos em relação ao sono, à saúde, ao uso do tempo e à divisão dos trabalhos remunerado e doméstico. Utilizamos este recurso por considerar que as disciplinas por si só não dariam conta da realidade a ser interpretada, o que está em consonância com a técnica de triangulação, segundo a qual os métodos qualitativos e quantitativos devem ser vistos como complementares, e não como campos rivais (Jick, 1979). Tal complementaridade e seu papel na compreensão da realidade social são discutidos por Minayo \& Sanchez (1993:247), segundo os quais “... se a relação entre o quantitativo e o qualitativo, entre objetividade e subjetividade não se reduz a um continuum, ela não pode ser pensada como oposição contraditória". Os autores enfatizam a natureza diferenciada desses enfoques, sugerindo que o debate trate das possibilidades e limites de cada abordagem em função da questão investigada. Neste estudo, as diferentes etapas da pesquisa implicam resultados de natureza diversa que, ao serem usados de forma colaborativa, revelam o caráter complementar que buscamos construir, como mostram alguns resultados discutidos a seguir.

$\mathrm{O}$ estudo cronobiológico revelou diferenças intra-amostra, como a duração e o número de episódios de sono por dia. Como o horário em que uma pessoa efetivamente dorme reflete não somente suas preferências e aspectos fisiológicos, mas também a influência das condi- ções domésticas, testamos a associação entre os horários de sono e a presença de crianças pequenas. Observamos uma tendência, nas trabalhadoras com filhos, a dormir menos de manhã e a dormir mais vezes por dia, quando comparadas às colegas que não os têm; nenhuma diferença significativa foi observada entre os homens com e sem filhos. Cabe notar que, embora a Cronobiologia considere os ritmos biológicos como fruto da interação entre fatores endógenos e exógenos, ou seja, decorrentes do ambiente externo (Minors \& Waterhouse, 1989), os dados cronobiológicos por si só não permitem avaliar em que medida o sono é influenciado por cada uma dessas fontes. Já a análise destes dados à luz das informações sóciodemográficas (no caso, a presença de filhos de até dez anos - etapa 1), revelou que as diferenças na amostra feminina podem ser atribuídas, ao menos em parte, à presença ou não de filhos, o que não se aplica à amostra masculina.

Os resultados reproduzem dados relativos a outro grupo de operárias do turno noturno, no qual constatamos, ainda, maior número de queixas relacionadas ao sono e à fadiga entre as trabalhadoras com filhos, quando comparadas às demais (Rotenberg et al., 2000b). Esses resultados encontram respaldo nos depoimentos aqui estudados, já que tanto as mulheres quanto os homens consideram que o trabalho doméstico interfere sobremaneira nos horários de sono. A associação entre o sono e a presença de crianças evidencia o caráter social subjacente às diferenças entre homens e mulheres. Assim, a menor duração do sono em trabalhadores com filhos tem sido atribuída ao ruído das crianças (Anderson \& Bremer, 1987), enquanto entre as mulheres, a influência dos filhos no sono é em geral relacionada às atividades de cuidado, como a interrupção do sono para preparar as refeições (Gadbois, 1981) ou para levar ou buscar as crianças na escola (Rotenberg, 1997).

A divisão do sono em dois episódios parece ter um caráter diferente nas amostras masculina e feminina, embora não haja diferença significativa entre as amostras quanto a esta variável. Entre as mulheres, dividir o sono (geralmente um matutino e outro vespertino) está associado à presença de filhos pequenos e à curta duração do sono matutino; já entre os homens, o número de episódios de sono/dia não se mostra associado nem à presença de filhos, nem à duração do sono matutino, como discutido por Rotenberg et al. (2000a). Se as diferenças entre os homens (dormir uma vez ou duas vezes por dia) podem ser atribuídas a diferenças individuais quanto às características fisio- 
lógicas do sono, como propõem Moreno et al. (2000), as diferenças na amostra feminina são mais facilmente atribuídas ao seu papel no cuidado dos filhos. Esta forma de "distribuir" o sono se coaduna com a fala de algumas delas, que mencionam dormir entre uma atividade e outra, precisando interromper o sono matutino para fazer o almoço, levar ou buscar os filhos na escola. Esta interpretação demanda a integração entre os resultados das três etapas da pesquisa, já que ela decorre dos dados cronobiológicos, aliados às informações demográficas e ao material obtido nas entrevistas.

A análise do impacto do trabalho noturno sob a ótica de gênero não deve usada como argumento para restringir a participação das mulheres no trabalho noturno (Bué \& Roux-Rossi, 1993), mas para inspirar ações que visem a conciliação do trabalho profissional e doméstico ou, o que é mais desejável, a maior eqüidade entre homens e mulheres na divisão do trabalho doméstico que possa minimamente corresponder ao movimento de saída das mulheres para o trabalho público.

Como já mencionado, o artigo aborda uma parte da pesquisa. Dada a necessária limitação de espaço, as relações de gênero no trabalho e sua associação com a saúde, assim como os dados ergonômicos serão tratados em outra publicação. A análise das falas se restringiu às vivências na troca do dia pela noite. Duas vertentes profundamente imbricadas a essas vivên-

\section{Agradecimentos}

À Estela Aquino, Greice Menezes e Angelo Soares nosso agradecimento pela leitura cuidadosa e crítica à versão anterior do artigo. Agradecemos também o apoio da Fundação Ford (Programa Interinstitucional de Treinamento em Metodologia de Pesquisa em Gênero, Sexualidade e Saúde Reprodutiva), do Conselho Nacional de Desenvolvimento Científico e Tecnológico (proc. 300.173/99-7 e PIBIC/FIOCRUZ) e a Fundação de Amparo à Pesquisa do Estado do Rio Janeiro (proc. E-26/151.008/96 e E-26/170.343/99). cias, quais sejam, as estratégias de organização do cotidiano e os fatores aos quais os/as trabalhadores/as atribuem a (im) possibilidade de adaptação ao trabalho merecerão outro espaço de discussão por sua relevância na abordagem do trabalho noturno. Essas questões contrapõem os problemas enfrentados por trabalhadores/as a aspectos compensatórios e alternativas para lidar com o trabalho noturno, não restringindo a análise aos danos e à vitimização destas pessoas.

No percurso da pesquisa, utilizamos diversas técnicas, procurando articular abordagens quantitativas e qualitativas. O desvendamento das vivências de homens e mulheres no exercício do trabalho noturno, sem negar a singularidade de cada indivíduo, permitiu revelar as regularidades presentes entre o grupo de trabalhadoras, quando comparadas aos trabalhadores. Ao mesmo tempo, os resultados trouxeram à tona diferenças no interior da população masculina e feminina. Os resultados revelaram a profunda interrelação entre as atividades profissionais e a vida doméstica como geradoras de impactos à saúde, ressaltando o caráter essencial das relações de gênero na compreensão da realidade vivida pelos que trabalham em horários não usuais. Quando a realização da jornada diurna compete com a premência de sono, é de se esperar que a vida como um todo sofra uma perda de qualidade, acirrando os impactos das diferenças homem-mulher.

\section{Referências}

AKERSTEDT, T., 1996. Work hours, sleepiness and accidents - Introduction and summary. Journal of Sleep Research, 4(Sup. 2):1-3.

ANDERSON, R. M. \& BREMER, D. A., 1987. Sleep duration at home and sleepiness on the job in rotating twelve-hour shift workers. Human Factors, 29:477-481.

AQUINO, E. M. L., 1996. Gênero, Trabalho e Hipertensão Arterial: Um Estudo de Trabalhadoras de Enfermagem em Salvador, Bahia. Tese de Doutorado, Salvador: Universidade Federal da Bahia.

BRITO, J., 1997. Uma proposta de vigilância em saúde do trabalhador com a ótica de gênero. Cadernos de Saúde Pública, 13(Sup. 2):141-144.

BROWN, D., 1982. Shiftwork, equality and women. Journal of Human Ergology, 11(Sup.):475-482. 
BRUSCHINI, C., 1990. Mulher, Casa e Família - Cotidiano nas Camadas Médias Paulistanas. São Paulo: Fundação Carlos Chagas.

BUÉ, J. \& ROUX-ROSSI, D., 1993. Le Travail de Nuit des Femmes. Paris: La Documentation Française.

DEKKER, D. K. \& TEPAS, D., 1990. Gender differences in permanent shiftworkers sleep behavior. In: Studies in Industrial Organizational Psychology (G. Costa, G. Cesana, K. Kogi \& A. Wedderburn, ed.), v. 10, pp. 77-82, Frankfurt: Peter Lang.

DUARTE, L. F. D., 1998. A outra saúde - Mental, psicossocial, físico moral? In: Saúde e Doença - Um Olhar Antropológico (P. C. Alves \& M. C. S. Minayo, org.), pp. 83-90, Rio de Janeiro: Editora Fiocruz.

FISCHER, F. M., 1996. Efeitos do trabalho em turnos fixos e de revezamento para a saúde dos trabalhadores. In: Seminário Nacional sobre Jornada de Trabalho em Turnos de Revezamento, Exposições e Resultados, pp. 5-8, São Paulo: Central Única dos Trabalhadores.

GADBOIS, C., 1981. Women on night shift: Interdependence of sleep and off-the-job activities. In: Night and Shift Work. Biological and Social Aspects (A. Reinberg, N. Vieux \& P. Andlauer, ed.), pp. 223-227, Oxford: Pergamon Press.

GARDUÑO, M. L.,1997. A saúde no trabalho de homens e mulheres: Uma visão de gênero. In: Trabalho, Saúde e Gênero na Era da Globalização. (E. M. Oliveira \& L. Scavone, org.), pp. 29-38, Goiânia: Editora $\mathrm{AB}$.

HALL, E. M.; JOHNSON, J. V.; FREDLUND, P. \& THEORELL, T., 1990. Double exposure: The combined impact of the home and work environments on mental strain and physical illness. In: Women's Work - An Inquiry into the Health Effects of Invisible and Visible Labor (E. M. Hall, ed.), pp. 1-27, Stockholm: Kangl Carolindska Medico Chirurgiska Institutet.

HÄRMÄ, M., 1995. Sleepiness and shiftwork: Individual differences. Journal of Sleep Research, 4(Sup. 2):57-61.

JICK, T. D., 1979. Mixing qualitative and quantitative methods: Triangulation in action. Administrative Science Quarterly, 24:602-611.

KERGOAT, D., 1989. Da divisão do trabalho entre os sexos. Tempo Social, Revista de Sociologia, 1:8896.

KNAUTH, P.; KIESWETTER, E., OTTMAN, W.; KARVONEN, M. \& RUTENFRANZ, J., 1983. Time-budget studies of policemen in weekly or swiftly rotating shift systems. Applied Ergonomics, 14:247-252.

LEE, K., 1992. Self-reported sleep disturbances in employed women. Sleep, 15:493-498.

MARQUES, N. \& MENNA-BARRETO, L., 1997. Cronobiologia - Princípios e Aplicações. São Paulo: Edusp/Rio de Janeiro:Editora Fiocruz.

MESSING, K., 1999. Integrating Gender in Ergonomic Analysis. Strategies for Transforming Women's Work. Brussels: European Trade Union Technical Bureau for Health and Safety.

MINAYO, M. C. S. \& SANCHEZ, O., 1993. Quantitativo-qualitativo: Oposição ou complementaridade? Cadernos de Saúde Pública, 9:239-262.

MINORS, D. \& WATERHOUSE, J., 1981. Circadian Rhythms and the Human. London: John Wright \& Sons.
MINORS, D. \& WATERHOUSE, J., 1989. Masking in humans: The problem and some attempts to solve it. Chronobiology International, 6:29-53.

MORENO, C.; ROTENBERG, L.; LOUZADA, F. M. \& MENNA-BARRETO, L., 2000. Two sleep patterns in night workers. In: Shiftwork in the 21st Century. Challenges for Research and Practice (S. Hornberger, P. Knauth, G. Costa, \& S. Folkard, ed.), pp. 323-326, Berlin: Peter Lang.

NACHREINER, F., 1998. Individual and social determinants of shiftwork tolerance. Scandinavian Journal of Work and Environmental Health, 24 (Sup. 3):35-42.

OGINSKA, H.; POKORSKI, J. \& OGINSKI, A., 1993. Gender, ageing, and shiftwork intolerance. $E r$ gonomics, 36:161-168.

ROBSON, M. \& WEDDERBURN, A., 1990. Women's shiftwork and their domestic commitments. In: Studies in Industrial Organizational Psychology (G. Costa, G. Cesana, K. Kogi \& A. Wedderburn, ed.), v. 10, pp. 137-142, Frankfurt: Peter Lang.

ROTENBERG, L., 1997. Trabalhando de Noite e Dormindo de Dia - Regularidade do Sono e Adaptação Psicológica em Operárias do Turno Noturno. Tese de Doutorado, São Paulo: Instituto de Psicologia, Universidade de São Paulo.

ROTENBERG, L.; PORTELA, L. F; MARCONDES, W. B.; MORENO, C. \& NASCIMENTO, C. P., 1999. Gênero e Trabalho Noturno: Sono, Cotidiano e Vivências de quem Troca o Dia pela Noite. Relatório de Pesquisa. Rio de Janeiro: Programa Interinstitucional de Treinamento em Metodologia de Pesquisa em Gênero, Sexualidade e Saúde Reprodutiva.

ROTENBERG, L.; PORTELA, L. F.; MARCONDES, W. B.; MORENO, C. \& NASCIMENTO, C. P., 2000a. Gender and diurnal sleep in night workers at a Brazilian industry. In: Shiftwork in the 21st Century. Challenges for Research and Practice (S. Hornberger, P. Knauth, G. Costa \& S. Folkard, ed.), pp. 305-309, Berlin: Peter Lang.

ROTENBERG, L.; PORTELA, L. F.; MORENO, C.; BENEDITO-SILVA, A. A. \& MENNA-BARRETO, L., $2000 \mathrm{~b}$. The amount of sleep, and complaints of fatigue and poor sleep in night-working women: The effects of having children. Biological Rhythm Research, 31:515-522.

SELIGMANN-SILVA, E., 1994. Desgaste Mental no Trabalho Dominado. Rio de Janeiro: Editora UFRJ/ Editora Cortez.

SORENSEN, G. \& VERBRUGGE, L. M., 1987. Women, work, and health. Annual Review of Public Health, 8:238-251.

VOLGER, A.; ERNEST, G.; NACHREINER, F. \& HÄNECKE, K., 1988. Common free time of family members under different shift systems. Applied Ergonomics, 19:213-218.

WALKER, J., 1985. Social problems of shiftwork. In: Hours of Work - Temporal Factors in Work-Scheduling (S. Folkard \& T. H. Monk, ed.), pp. 211-225, Chichester: Wiley.

ZAR, J. H., 1996. Biostatistical Analysis. New Jersey: Prentice Hall. 